\title{
Ciência e capitalismo
}

Júlia Paula Motta de Souza

Doutoranda em Filosofia e História da Educação pela Unicamp

\section{Resumo}

Este artigo reflete sobre as relações entre a ciência moderna e o capitalismo. Historicamente a ciência moderna nasce ligada ao capitalismo, pretendendo-se impor como saber hegemônico, livre de valores e baseada em quantificações. $\mathrm{Na}$ presente fase neoliberal do capitalismo, na qual se acentua a tendência a transformar tudo em mercadoria, a ciência vem sendo mercantilizada e as condições de trabalho dos pesquisadores vem sendo degradadas. Um dos aspectos é o surto avaliatório, que quantifica a produção acadêmica. No entanto, os pesquisadores podem exercer sua responsabilidade social que inicia com uma reflexão crítica.

Palavras-chave: Ciência Moderna; Capitalismo; Taylorismo Acadêmico.

\section{Resumen}

Este artículo refleja sobre las relaciones entre la ciencia moderna y el capitalismo. Históricamente la ciencia moderna nace conectada al capitalismo, pretendiéndose imponer cómo saber hegemônico, libre de valores y basada en quantificações. En la presente fase neoliberal del capitalismo, en la cual se acentúa la tendencia a transformar todo en mercancía, la ciencia viene siendo mercantilizada y las condiciones de trabajo de los investigadores viene siendo degradadas. Uno de los aspectos es el surto avaliatório, que quantifica la producción académica. Sin embargo, los investigadores pueden ejercer su responsabilidad social que inicia con una reflexión crítica.

Palabras clave: Ciencia Moderna; El Capitalismo; El Taylorismo Académico. 


\section{Introdução}

ciência moderna principiou com a chamada revolução científica
do século XVI e pretendeu, desde a sua origem, impor-se como
saber verdadeiro e hegemônico.

A visão de mundo que imperava quando do surgimento da ciência moderna era a síntese aristotélica. O filósofo Aristóteles, possuidor de uma inteligência admirável, propõe toda uma cosmologia que acaba por se configurar num modo de pensar que se estenderia por muitos séculos. Em suas reflexões, por um lado originais e por outro reformuladoras da tradição grega, o Cosmos é concebido como um todo ordenado. Cada coisa tem seu lugar próprio e natural, e além disso, as coisas buscam seu lugar natural.

A Terra, entendida como esférica e imóvel, se encontra no centro de um universo finito e limitado pela esfera das estrelas. O cosmos é totalmente hierarquizado e composto por dois mundos completamente diferentes: o mundo sublunar (das coisas perecíveis, que se deterioram) e o mundo supralunar (constituído pela quintaessência, o éter: imperecível, divino, fino, transparente).

Os astros são condensações de éter e tem órbita circular em torno da Terra. O que move a última esfera, a das estrelas, é o primeiro motor imóvel. Prova-se com este primeiro movimento a existência de Deus, que é puro ato e transfere seu movimento através do éter.

Séculos se passaram com esse pano de fundo filosófico-teológico a habitar a mente dos europeus. No entanto, algumas rupturas significativas aconteceram que começaram a preparar o solo para a semente da Modernidade poder germinar.

No aspecto econômico, político e social há a passagem do feudalismo para o capitalismo e no aspecto religioso ocorrem as reformas protestantes, que fortalecem o grupo dos protestastes, mais sintonizados com a burguesia, em detrimento dos católicos, mais ligados ao poder monáquico. 
Todo esse contexto histórico favorável, ventilou novos ares e favoreceu o desenvolvimento de uma transformação muito especial, chamada posteriormente de revolução científica moderna.

Espaços filosóficos são abertos possibilitando que alguns cientistas, sobretudo astrônomos, comecem a olhar o mundo por uma nova janela. A lógica aristotélica passa a ser questionada. Copérnico, apesar de ainda envolto numa visão mágica e mística do mundo, afirma que a Terra nem é imóvel, nem tampouco é o centro do Universo, propondo pela primeira vez o heliocentrismo.

Mas, é Galileu quem de fato introduz um corte epistemológico, rompendo com todo o sistema de representação do mundo antigo e do mundo medieval. Galileu é o primeiro espírito verdadeiramente moderno. Foi ele o verdadeiro fundador da ciência moderna, quem lança as bases da concepção mecanicista de mundo, definindo o ideal científico de rigor e inaugurando a inteligibilidade mecanicista (Japiassu, 1978, p. 26-9).

Galileu desafia os homens de seu tempo a decifrar a linguagem geométrica e matemática da natureza. A partir dele, o universo passa a ser compreendido sob a forma de um contínuo físico de extensão indefinida, no interior do qual os fatos físicos são matematicamente calculáveis. O mundo deixa de ser finito e hierarquicamente ordenado.

Esta nova inteligibilidade do mundo veio destruir o esquema de um Cosmos organizado hierarquicamente no interior de um espaço fechado e impregnado de ressonâncias mítico-religiosas. Esse corte epistemológico representa a passagem das simpatias e antipatias, das afinidades e analogias, dos cálculos esotéricos e alquimias, para a Razão. É o desencantamento do mundo.

Ao questionar o equilíbrio milenar do universo, Galileu questiona também todo o significado da existência humana, pois o mundo geométrico de Galileu não tem nenhuma relação com a presença humana e nem com a história da salvação. O mundo simbólico, garantido por Deus, não é mais referência para a existência humana. O domínio físico fica desligado da ordem metafísica. A verdade geométrica do mundo é indiferente à verdade 
existencial do homem. O "lugar natural" do homem não é mais o centro do universo. Essa nova estrutura racional da realidade exigia também novos homens: seres de razão.

Os conceitos subjetivos e valorativos não se encaixam na nova ontologia. O Cosmos, que antes falava, ditava ordens, acalentava, confortava, agora é um espaço infinito e silencioso, que aterroriza. O que fascina Galileu é a redução do real ao geométrico. A natureza é vista como uma máquina, um conjunto de mecanismos cujas leis precisam ser descobertas. A ciência moderna já nasce mecanicista. Quando a Natureza deixa de ser deificada, deixando de ser uma espécie de organismo governado por um princípio imanente, a metáfora da máquina passa a ser utilizada para descrever os fenômenos da vida.

Neste momento de incertezas e confusão, no qual o homem se vê privado das convicções que as antigas normas lhes davam, surge Descartes, propondo uma nova metafísica. Considerado o primeiro grande filósofo moderno, ele rompe com uma série de padrões de conhecimento com os quais havia sido educado. Rompe com o princípio de autoridade, afirmando que cada um deve examinar sua própria razão: "Eu não podia escolher ninguém cujas opiniões me parecessem dever ser preferidas às dos outros, $e$ encontrava-me como que obrigado a procurar conduzir a mim próprio." (Descartes, Discurso do método e as paixões da alma, 1984, p.16). Defende a idéia da luz natural da razão, afirmando que a razão é autônoma e tem seus próprios critérios, e por isso, conhece sempre da mesma forma.

Este filósofo, revolucionário e ambicioso no campo do conhecimento, acreditava que poderia chegar a uma verdade absoluta, a um conhecimento certo e verdadeiro. Defendeu seu projeto de ciência universal, baseado nessa unidade do saber. Acreditava que o método para chegar a essa ciência universal era a matemática. Para Descartes, a verdade é una, mas é necessário separar para conhecer. Comparava o mundo a um relógio, num exemplo de procedimento matemático.

De raciocínio lógico brilhante, as bases da metafísica fundada por Descartes ainda influenciam fortemente toda mentalidade ocidental. 
Descartes sonhava com uma humanidade liberada pela máquina de sua sujeição às forças naturais. Toda civilização ocidental nasce deste sonho mecanicista.

Importante perceber o qual totalitário foi o modelo que pautou a revolução científica no século XVI, negando o caráter racional a todas as formas de conhecimento que não se pautavam pelos seus princípios epistemológicos e pelas suas regras metodológicas. Esse autoritarismo é sua característica fundamental e está bem patente na atitude mental dos protagonistas, na sua admiração perante as próprias descobertas e na exaltação com que se comparam com seus contemporâneos. Vejamos Descartes (Discurso do método e as paixões da alma, 1984, p.6), imbuído da certeza de ser o descobridor de uma verdade única e absoluta, como fala de seu método científico:

Porque já colhi dele tais frutos que, embora no juízo que faço de mim próprio, procure sempre inclinar-me mais para o lado da desconfiança do que para o da presunção, e embora, olhando com o olhar de filósofo as diversas ações e empreendimentos de todos os homens, não haja quase nenhuma que não me pareça vã e inútil, não deixo de receber uma extrema satisfação com o progresso que julgo ter feito em busca da verdade e de conhecer tais esperanças para o futuro que, se entre as ocupações dos homens, puramente homens, alguma há que seja solidamente boa e importante, ouso crer que é aquela que escolhi.

Essa nova visão de mundo e da vida conduz a uma separação total entre natureza e ser humano. A natureza é tão somente extensão e movimento, é passiva e eterna, mecanismos cujos elementos se podem desmontar e depois relacionar sob a forma de leis; não tem qualquer outra qualidade que nos impeça de desvendar seus mistérios, desvendamento que não é contemplativo, mas antes ativo, já que visa conhecer a natureza para a dominar e controlar. Segundo Bacon, a ciência fará da pessoa humana o senhor e o possuidor da natureza.

As idéias matemáticas presidem este novo tipo de conhecimento sobre a natureza. Esta fornece à ciência moderna, não só o instrumento privilegiado de análise, como também a lógica de investigação e também o modelo de representação da própria estrutura da matéria. Deste lugar central 
da matemática na ciência moderna deriva uma conseqüência importante: conhecer significa quantificar.

O determinismo mecanicista é o horizonte certo de uma forma de conhecimento que se pretende utilitário, funcional e quantificador, reconhecido menos pela capacidade de compreender profundamente o real do que pela capacidade de dominá-lo e controlá-lo.

No plano social, é esse também o horizonte cognitivo mais adequado aos interesses da burguesia ascendente. Assim, o privilégio epistemológico deste novo tipo de conhecimento se tornou também um privilégio sociológico.

A ciência não é fundadora da modernidade, mas surge no seu âmbito e fortalece-se na medida em que consegue animar e legitimar o espírito da época de negação da autoridade da Igreja e de controle e poder sobre tudo e todos.

Dessa forma, o surgimento da ciência moderna está ligada ao nascimento do capitalismo e partilha com ele o desejo de dominar, explorar e manipular a natureza e os homens.

A burguesia estava pronta pra tomar o poder político sobre as ruínas das instituições feudais e fez substituir o culto da divindade pelo culto da razão. Ao se apropriar do discurso racionalista a burguesia substituiu a vontade de Deus pela lei dos mercados.

Nesta nova forma de apreensão da realidade os fatos "objetivos", "racionais" e "verdadeiros" são separados dos valores "subjetivos", "relativos" e "morais". Essa separação entre fatos e valores, em oposição ao que prevalecia na visão de mundo aristotélica, impregnou profundamente toda a cultura ocidental. Na disputa de Galileu com a Igreja Católica, a reivindicação de neutralidade nasceu junto com a ciência moderna. A ciência nasce pretendo-se livre de valores. Ao mesmo tempo que, contraditoriamente, pretende-se, ela própria, ser um valor universal.

A ciência desencantada, fria, dura e neutra, acaba por legitimar uma relação de domínio e exploração da natureza. Se o conhecimento proposto pela ciência moderna é o único verdadeiro e para ela o mundo é uma imensa 
coleção de fatos desprovidos de valor intrínseco, não há restrição ética para a dominação da natureza, na tentativa de fazê-la satisfazer todas as necessidades e desejos dos homens.

Marx (1973, p. 40) expressou lucidamente a associação do desencantamento do mundo e da dominação da natureza pelo capitalismo no seguinte trecho:

[...] pela primeira vez a natureza se torna puramente um objeto para a humanidade, puramente uma questão de utilidade; ela deixa de ser reconhecida como um poder em si mesma; e a descoberta teórica de suas leis autônomas aparece meramente como um estratagema para subjugá-la às necessidades humanas, quer como objeto de consumo, quer como meio de produção.

Os mesmos princípios que encontramos na origem da ciência moderna, continuam presentes na atual fase neoliberal do capitalismo. A ciência continua pretendendo-se neutra, livre de valores, factual, experimental, um valor universal acima do bem do mal, hierarquicamente superior aos demais conhecimentos, baseada em quantificações e valoriza cada vez mais o controle, a dominação e a exploração da natureza.

Desde o início, a ciência, a despeito de se proclamar livre de qualquer ideologia, criou a sua própria ideologia, passando a ter as várias características de uma nova religião, o cientificismo, que exerce um incrível poder de fascínio sobre as massas humanas, devido a seus êxitos inegáveis.

$\mathrm{O}$ cientificismo continua profundamente arraigado nas mentalidades. O poder da palavra "ciência" sobre o senso comum surge como uma espécie de verdade revelada, com uma textura quase mágica, o oráculo dos tempos modernos. Para o comum dos mortais, a ciência se apresenta como uma espécie de magia negra, sua autoridade sendo ao mesmo tempo indiscutível e incompreensível.

O cientificismo, ao se apresentar com esse caráter meio religioso, tem uma característica bastante dogmática, de acordo com as religiões mais ortodoxas e fundamentalistas: uma extrema intolerância a todo e qualquer outro saber que não seja ela mesma. Se prosseguirmos na comparação do cientificismo com uma religião, os seus Sumos Sacerdotes são os próprios 
cientistas, que tem por missão revelar o "saber sagrado" com uma linguagem cifrada, meio esotérica, aos não-iniciados.

Esse cientificismo religioso dinamizou uma outra "religião", a da produção crescente e do crescimento contínuo, num progresso indefinido da tecnologia. O principal valor da ciência é o seu valor instrumental como geradora de tecnologias, ou seja, como meio para incrementar a capacidade humana de controle da natureza. A ciência, ou a ideologia cientificista, pretende impor-se como o único meio realmente eficaz para o tratamento de qualquer problemática humana, capaz de eliminar todas as dúvidas e trazer a felicidade. Tudo o que o método experimental não pode assumir é delegado ao domínio do "irracional", "emocional" ou "subjetivo".

Sendo assim, a ciência tem o privilégio epistemológico e sociológico desde suas origens nas sociedades ocidentais, e continua defendendo esses privilégios com unhas e dentes. Porém, dentre todas essas semelhanças reeditadas no século XXI, existe um fator novo, como se o feitiço tivesse virado contra o feiticeiro e a própria ciência está sendo alvo de quantificação, em função da mercantilização que vem sofrendo.

$\mathrm{Na}$ atual fase neoliberal do capitalismo, na qual se intensifica a propensão do sistema a transformar todos os tipos de bens em mercadorias, temos a reforma universitária. Esta tem o suporte do Banco Mundial, cuja visão da educação é mercantil. A reforma universitária é concebida para submeter o processo educacional ao mercado. A educação perde todos os seus elementos não-mercantis (formação humanista, pensamento crítico) tornando-se mera mercadoria.

Lacey (1998) sugere que a natureza essencialmente quantitativa compartilhada, de um lado pela forma mercadoria, de outro, pela ciência moderna, é responsável por uma relação mutuamente reforçadora entre o capitalismo e a ciência moderna. O capitalismo matematiza a vida social, e assim, numa relação mutuamente reforçadora, favorece e tem seu avanço favorecido pela visão da realidade social inspirada na ciência moderna, com seu viés quantitativo. 
Segundo Oliveira (2002) a reforma neoliberal da Universidade pode ser interpretada como a imposição do taylorismo na academia. A natureza quantitativa da forma mercadoria e da ciência moderna nos faz escravos da quantidade. Um dos traços mais marcantes, e mais conhecidos do taylorismo é a importância do papel atribuído às medições. No taylorismo, portanto, estão associadas, reforçando-se mutuamente, as tendências quantificadoras do capitalismo e da ciência moderna.

No taylorismo o aumento da produtividade é posto como o valor mais importante, acima de qualquer outro valor, como a satisfação no trabalho, a saúde e o bem-estar dos trabalhadores. O bem-estar do trabalhador é promovido apenas quando pode resultar em aumento da produtividade, como nos programas de ginástica, projetos de paisagismo, etc. No entanto, o mais comum é que aumentos de produtividade sejam obtidos às custas dos trabalhadores.

Uma das manifestações do produtivismo taylorista na universidade é a competição compulsiva e o avanço do individualismo, bem no espírito neoliberal, através da imposição dos duros processos de avaliação que os pesquisadores têm de se submeter em busca de recursos.

Faz parte da reforma universitária o surto avaliatório, que pretende quantificar a ciência para mercantilizá-la, apoiando-se para isso nos paradigmas da própria ciência moderna presentes desde sua origem, que postula que só conhecemos o que podemos medir e quantificar.

A ciência, ao impor-se como a única fonte verdadeira de conhecimento válido, apoiou-se na matematização e quantificação do mundo. Com este pano de fundo, a voracidade do capitalismo impõe o viés quantitativo nas práticas de avaliação aplicadas ao trabalho acadêmico, pois uma das características mais evidentes do surto avaliatório é seu viés quantitativo.

A distribuição de verbas para pesquisa se realiza de acordo com a classificação do currículo do pesquisador a partir de uma pontuação detalhada de cada atividade considerada relevante, segundo os critérios dos órgãos de fomento. Cada atividade tem uma pontuação específica, sendo 
especialmente valorizada a publicação de artigos, que podem variar numa escala de pontuação que vai do máximo, que são os artigos completos em periódicos indexados internacionais e de grande impacto na comunidade científica, até o mínimo, que são aqueles artigos resumidos em periódicos regionais de baixo impacto.

Neste sistema, o atributo essencial de um pesquisador é a sua capacidade de publicar artigos em inglês. Considera-se que um artigo publicado em inglês é melhor do que qualquer outro publicado em qualquer outra língua, o que obriga os pesquisadores a adequarem-se aos temas e problemas propostos pela comunidade científica internacional, além de investir tempo, energia e recursos no domínio do inglês.

A competição e o stress que isso gera têm conseqüências negativas tanto para a saúde dos trabalhadores, quanto para a sociedade que financia a pesquisa.

A contínua geração de estresse oriundo das exigências de produtividade, sem correspondente valorização econômica, passando pela instabilidade no emprego, vem adoecendo os atores envolvidos, gerando sofrimentos físicos e psíquicos, que podem ser observados pelo uso de antidepressivos, ansiolíticos, etc. Houve, inclusive, uma sondagem feita na Internet pela revista Nature, a respeito do consumo, por cientistas, de drogas psicotrópicas com o objetivo de melhorar o desempenho cognitivo. Dentro os 1.400 cientistas que responderam à sondagem, cerca de $20 \%$ relataram adotar essa prática, para "estimular o foco, concentração ou memória" (Maher, 2008, p.1157), sendo a Ritalina a droga mais usada.

O aumento da competição, a escassez de emprego que leva muitos doutores a trabalharem com remuneração de mestres, a diminuição de recursos, o prevalecimento do número de publicações internacionais sobre a produção de conhecimento relevante socialmente... tudo isso tem gerado grande sofrimento por parte dos pesquisadores, abandono de carreira, declínio da criatividade, diminuição de jovens dispostos a seguir a carreira acadêmica... enfim, uma combinação de fatores que podem levar ao sucateamento da pesquisa no Brasil. 
Os pesquisadores, apesar de todo o esforço que empregam para serem produtivos, não são máquinas e não poderão ter saúde se continuarem sacrificando repouso, lazer e férias em favor do trabalho.

A sociedade também sofre as conseqüências deste sistema de avaliação, que "obriga" os pesquisadores a se desvincularem da sociedade que os dá origem e sustenta, para brigar por um lugar ao sol no cenário internacional. Os pesquisadores, mesmo inseridos e sustentados pela sociedade brasileira, acabam não contribuindo como poderiam para a diminuição dos imensos problemas que nela existem, pois na competição pelos recursos, o que "conta" são as revistas internacionais e não os problemas regionais.

No melhor dos mundos, os pesquisadores teriam energia, fôlego, tempo e disposição para escrever tanto para periódicos na língua inglesa quanto em português, mas a prática tem mostrado que isso é impossível. O que vemos é uma pressão tão grande em busca destas publicações estrangeiras, que quase não sobra tempo para a vida pessoal e familiar. Lazer passa a ser palavra inexistente. Tempo livre, para o pesquisador, significa um tempo no qual ele faz o que não conseguiu realizar no seu tempo de trabalho.

Não há igualdade de oportunidades no mundo em que vivemos em nenhum setor e na ciência não é diferente. Os pesquisadores brasileiros têm que concorrer no ranking com os países centrais, só que é como se eles fossem "de carro" e os brasileiros "de bicicleta", tal é a diferença tecnológica que existe para realização das pesquisas.

Como não há igualdade de oportunidades, não pode haver uma ciência "universal", mas sim distribuição desigual do conhecimento e dos recursos em função das disparidades históricas e sociais entre as diferentes comunidades científicas em suas origens. É fácil verificar que as denominadas publicações "internacionais" raramente são de fato internacionais no seu conteúdo, nos seus leitores e no corpo editorial, mas sim expressões evidentes dos interesses próprios da comunidade de língua inglesa. 
Rodrigues (2007), em artigo publicado na RBCE com o título Publicar mais ou melhor? O Tamanduá Olímpico, afirma:

há suspeita de que a maioria dos resultados publicados é falsa e que os periódicos biomédicos são uma extensão da divisão de marketing das companhias farmacêuticas e Antony Barnett, redator do The Observer (Inglaterra), afirma que as gigantes farmacêuticas contratam autores fantasmas para produzir artigos e colocam o nome de médicos neles. A credibilidade do sistema de publicações científicas tem sido tão questionada diante das pressões da competição e do mercado que foi criado um site exclusivamente para detectar pesquisadores que estão relacionados à indústria ou a interesses econômicos e políticos.

Assim a competição internacional não é sinônimo de alta qualidade científica e, menos do que "boa ciência", o conteúdo das publicações pode estar sendo determinado pelos temas de interesse daqueles que controlam financeiramente a pesquisa no mundo desenvolvido. A concentração de recursos e a competição generalizada estão fazendo parte daqueles containeres importados que trazem a maquinaria complexa do colonialismo contemporâneo. Neste sentido, a pressão pela publicação em inglês pode ser vista como uma nova forma de colonialismo e a "verdade" dos periódicos internacionais pode e deve ser questionada.

Um exemplo deste questionamento é o posicionamento de 45 periódicos da área de estudos da ciência, reagindo a uma iniciativa da European Science Foundation que pretendia estabelecer para todo o campo das humanidades um sistema de classificação de periódicos da mesma natureza que o sistema Qualis da CAPES.

Este editorial conjunto, publicado pelo Jornal da Ciência no dia 09/10/08, é uma reação contra a graduação de periódicos na área das humanidades e também um questionamento sobre os critérios com que os periódicos são classificados e a confusão de internacionalidade com qualidade, particularmente prejudicial para periódicos especializados e publicados em outras línguas que não o inglês. Diz o editorial: "a qualidade dos periódicos não pode ser separada de seu conteúdo e seus processos de seleção. Pesquisa de alto nível pode ser publicada em qualquer veículo e em qualquer língua". 


\section{Conclusões}

É importante que toda comunidade científica se posicione, pois a supervalorização das publicações em inglês pode liquidar de vez com as publicações regionais. Ao contrário, se os artigos em português fossem valorizados, haveria artigos de mais qualidade nas revistas nacionais e o acesso à informação científica seria muito mais abrangente nos sistemas de procura eletrônicos, especialmente no Portal CAPES, mantido com recursos públicos.

Num novo modelo de avaliação o muito poderia ser substituído pelo melhor, com ênfase nos critérios de relevância do conhecimento produzido e não no prestígio internacional do meio de publicação. No mínimo, as publicações nacionais e internacionais deveriam ter a mesma pontuação.

Deve haver também um maior diálogo com a sociedade, no sentido de ampliar os mecanismos de participação da sociedade que sustenta a prática científica na definição dos projetos de pesquisa que devem ser financiados.

Exemplos disso são as experiências européias dos "science shops" e as “community-based research" dos Estados Unidos, assim como o People's Science na Índia, além de outras colaborações entre pesquisadores e ativistas no mundo todo, que procuram mobilizar recursos científicos para responder a problemas de populações locais, de comunidades, de grupos de cidadãos, através de formas de participação de todos os interessados nos processos de decisão. Os critérios de avaliação destes conhecimentos passam, não pela confrontação com padrões universais, idealizados, do que é a "boa" ciência, mas por critérios situados, que procuram interrogar o "como" e o "para que" da produção do conhecimento, isto é, a relação entre o trabalho de construção de conhecimentos e as suas conseqüências ou efeitos.

No diálogo com a sociedade o pesquisador deve tentar atender as necessidades dessa sociedade e produzir conhecimento para aqueles que financiam a sua prática, a sociedade a qual pertencem historicamente e que os sustenta com seu trabalho na forma de impostos. 
No entanto, para haver diálogo com a sociedade em condições de simetria é fundamental aos pesquisadores despojarem-se de sua arrogância cientificista e perceberem que o conhecimento científico é apenas um entre tantos saberes válidos e verdadeiros. Deve haver um reconhecimento mútuo do caráter parcial e situado de todos os conhecimentos e uma renúncia por parte dos acadêmicos à desqualificação de saberes rotulados de "nãocientíficos".

A ciência é uma prática social e não detém o monopólio da racionalidade. É apenas uma forma de conhecimento e interação com a natureza entre outras, que tem igualmente o direito de existir. Admitir os limites do conhecimento científico é o primeiro passo para o exercício da responsabilidade social.

Para exercer a responsabilidade social os pesquisadores precisam refletir sobre sua prática, sobre o significado e as conseqüências sociais de seu próprio trabalho. Estas reflexões, mesmo que resultem em publicações, não "contam" como contribuição daquela área específica, o que pode levar alguns pesquisadores a considerar essas reflexões como perda de tempo do trabalho realmente produtivo.

Dessa forma, a reforma universitária com seus critérios neoliberais de avaliação vem impedindo o pleno exercício da responsabilidade social dos pesquisadores. É preciso lutar pela des-taylorização do trabalho acadêmico para que os pesquisadores possam desenvolver um interesse e uma competência filosófica para problematizar sua prática científica. Precisamos de reflexão ética e moral para poder controlar o próprio dinamismo da sociedade científica.

Em vista dos impasses e das imensas contradições que vivemos e considerando a força e a importância da ciência e da tecnologia no mundo, a ciência não pode mais ser isolada esfera valorativa. A ciência não é neutra, não é um valor universal e nem pode ser posta acima das outras formas de conhecimento. Precisamos perceber o quanto de pretensão, arrogância e prepotência existem nessa forma de autonomia baseada na neutralidade. Embora tenha tido uma função histórica importante, libertando a ciência da 
autoridade da Igreja, ela é hoje inaceitável para os setores mais esclarecidos da sociedade.

O cientificismo contrasta com valores como a cooperação, o diálogo, o respeito. Temos que rever e transformar esses valores. Para a ciência deixar de ser subserviente aos valores do capital, ela deve fazer um autoexame, aceitar as críticas dirigidas a ela, refletir e passar a atender os interesses e necessidades da população e não mais do capital.

\section{Referências}

DESCARTES, R. Discurso do método e as paixões da alma. Lisboa: Sá da Costa, 1984.

JAPIASSU, H. Nascimento e Morte das Ciências Humanas. Rio de Janeiro: Francisco Alves Editora, 1978.

JORNAL DA CIÊNCIA. www.jornaldaciencia.org.br/contato.jsp em 09/10/2008.

LACEY, H. Valores e Atividade Científica. São Paulo: Discurso editorial, 1998.

MARX, K. Grundrisse. Harmondsworth: Penguin, 1973.

OLIVEIRA, M. B. A ciência que queremos e a mercantilização da universidade. In: Loureiro, I; Del-Masso, M. C. (orgs.), Tempos de greve na universidade pública. Marília: Unesp Publicações, 2002, pp.17-41.

MAHER, B. P. Look who's doping. In: Nature, 2008.

RODRIGUES, L. O. C. Publicar mais ou melhor? O tamanduá olímpico. In: Revista Brasileira de Ciências do Esporte, v. 29, p. 35-48, 2007. 